Research Article

\title{
Numerical Evaluation of Reinforced Concrete Columns Retrofitted with FRP for Blast Mitigation
}

\author{
Jing Dong $(\mathbb{D}$, Junhai Zhao $(\mathbb{D}$, and Dongfang Zhang $(\mathbb{D}$ \\ School of Civil Engineering, Chang'an University, Xi'an 710061, China \\ Correspondence should be addressed to Junhai Zhao; zhaojh@chd.edu.cn
}

Received 7 April 2020; Revised 10 August 2020; Accepted 7 September 2020; Published 16 September 2020

Academic Editor: Chiara Bedon

Copyright (c) 2020 Jing Dong et al. This is an open access article distributed under the Creative Commons Attribution License, which permits unrestricted use, distribution, and reproduction in any medium, provided the original work is properly cited.

\begin{abstract}
Fiber reinforced polymer (FRP) material is commonly applied in retrofitting structures due to the advantages of high strength and well corrosion resistance. Previous studies indicated that retrofitting with FRP sheet was an effective way for protecting the existing structures to resist the blast loads, but little research made comprehensive comparison study on the blast response of RC columns with different retrofitting strategies. This paper proposed a series of FRP retrofitting strategies and evaluated their effect on blast mitigation using numerical analysis approach. Comparison studies were conducted on the effect of FRP type, FRP thickness, and retrofitting mode on blast mitigation. A finite element model of RC columns retrofitted with FRP under blast loading was developed. The model considered the strain rate effect of steel and concrete and the orthotropic property of FRP composites. The reliability of the proposed model was validated against the data from a field blast test. Based on the verified model, the blast responses of RC columns with different retrofitting strategies were numerically investigated. According to the result analysis, appropriate FRP type, FRP thickness, retrofitting mode, and retrofitting length were recommended.
\end{abstract}

\section{Introduction}

Blast accidents caused by deliberate terrorist attacks and improper operations occur frequently. The blast accidents and their secondary disasters may bring about casualties and economic losses. Additionally, structures easily damage or even collapse when exposed to severe blast loading. For reducing the damage after explosion, the blast protection of buildings should be taken into consideration in the design phase. Besides, it is an urgent and significant task to retrofit the existing structures for blast mitigation.

In order to enhance the blast resistance of the existing building structures, previous studies provide valuable achievements on the retrofitting strategies with some high strength or high stiffness materials bonding on the surface of the structure, such as fiber reinforced polymer (FRP), steel plates, and aluminium foam. These retrofitting schemes can improve the blast resistance performance of the structures in different degrees [1]. Among those retrofitting materials, FRP is the most commonly used material [2]. FRP is a high performance and low weight composite material with well corrosion resistance [3]. Reinforced concrete (RC) structure is widely applied in civil engineering. Recently, many researchers have made attempts to utilize FRP materials for blast mitigation of RC structures. Researchers in Karagozian \& Case Science and Engineering Consulting Firm initially investigated the use of composite material to resist blast effects [4-6]. Buchan and Chen [7] and Zhao et al. [8] presented reviews on blast resistance of reinforced concrete structures retrofitted with FRP composites. The reviews pointed out that the blast resistance of a structure was obviously enhanced with FRP. In terms of type of FRP material studied, there are many research papers on carbon fiber reinforced polymer (CFRP) and glass fiber reinforced polymer (GFRP), but few on other types of FRP material. From the perspective of research approach, scaled blast test and numerical simulation are the common research methods, while few studies utilize the theoretical analysis due to the complication of blast load. Some representative studies are as follows. For the RC slabs and walls retrofitted with FRP, Silva and $\mathrm{Lu}$ [9] carried out blast tests on RC slabs strengthened with CFRP. The strengthening schemes of 
slabs included one-side retrofitting and two-side retrofitting. The two-side retrofitting scheme could significantly increase the blast resistance while the one-side retrofitting scheme showed little effect on blast protection of the RC slab. Nam et al. $[10,11]$ proposed the numerical model of GFRPretrofitted RC slab and CFRP-retrofitted RC wall subjected to blast loading. The numerical model considered the strain rate effect and FRP debonding failure and was validated against the previous experimental data. Tanapornraweekit et al. $[12,13]$ conducted two independent blast tests and numerical simulation on GFRP and CFRP strengthened RC slabs. Based on this study, Lin and Zhang [14] numerically studied the effect of thickness of GFRP sheets on blast mitigation. The results indicated that the deflections of $\mathrm{RC}$ slabs under blast loading decreased with the increase of GFRP thickness. Kong et al. [15] numerically analyzed the blast response of RC slabs strengthened with aramid fiber reinforced polymer (AFRP). The effects of AFRP layers and four different strengthening modes were discussed. Three AFRP layers was recommended in the study as the appropriate retrofitting number of layers. Additionally, wholly strengthened RC slabs showed better blast resistance than strip-like and crosswise strengthened RC slabs. For the RC columns retrofitted with FRP, Crawford et al. [4] experimentally and numerically studied the blast effect of conventional RC column, RC column retrofitted with steel, and RC column retrofitted with FRP. In most of the cases studied, retrofitting the column with steel or FRP wraps can effectively prevent collapse. Mutalib and Hao [16] investigated the P-I diagrams of RC columns strengthened with CFRP. The different FRP strengthening modes were innovatively studied, including strip, wrap, and both wrap and strip strengthening. Rodriguez-Nikl et al. [17] tested nine rectangular RC columns with and without FRP. Load-deflection curves of the column and stain of FRP were obtained. Nevertheless, the test was performed in the laboratory with lateral quasi-static load, which simulated the blast loading. Similarly, Jacques et al. [18] implemented RC columns retrofitted with GFRP under simulated blast loading. Different from the above research, shock-tube test setup was adopted to generate the simulated blast loading. Full-scale field blast test of RC column retrofitted with GFRP was carried out by Qasrawi et al. [19]. Results indicate that retrofitting with GRRP is reliable to reduce the residual displacement and local damage of the column. Liu et al. $[20,21]$ studied the RC piers retrofitted with CFRP under contact and noncontact explosion. The specimen in the field blast test included unretrofitted column, one-layer CFRPretrofitted column, two-layer CFRP-retrofitted column, and three-layer CFRP-retrofitted column. With the increase of the CFRP layers, the blast resistance of the columns performs better. In summary, all the previous research results demonstrated that the RC structures retrofitted with FRP exhibited better blast resistance compared with conventional $\mathrm{RC}$ structures. However, the blast responses of RC structures retrofitted with CFRP, GFRP, and AFRP were experimentally or numerically studied separately. Parametric analysis substantially focused on the material strength, reinforcement ratio, and scaled distance. Only some studies mentioned the effect of thickness or strengthening modes of a particular FRP material. The comparative studies on different FRP retrofitting strategies were still insufficient, especially for FRP-retrofitted RC columns. It is necessary to implement a comprehensive investigation on the blast performance of RC columns retrofitted with different retrofitting schemes including FRP type, FRP thickness, and retrofitting modes.

In this study, a series of retrofitting strategies were proposed for improving the blast resistance of reinforced concrete columns. Different FRP types, FRP thicknesses, and retrofitting modes were considered in the proposed retrofitting designs. The blast responses of these retrofitting strategies were evaluated and compared using the numerical analysis method. First, a finite element model of the RC columns retrofitted with FRP under blast loading was developed with the consideration of strain rate effect. The numerical analysis was conducted by the explicit nonlinear finite element program LS-DYNA. The reliability of the proposed numerical model was verified against the relevant experimental results. Furthermore, a series of RC columns retrofitted with FRP under identical blast condition were numerically investigated based on the verified model. The blast responses of the columns were compared, and the effect of different retrofitting strategies was discussed. The reported findings in this study can serve as available reference for blast mitigation of structural design and retrofitting.

\section{Design of RC Columns Retrofitted with FRP}

In order to investigate the effect of RC columns with different retrofitting strategies on blast mitigation, this paper presents a series of FRP retrofitting schemes, including different FRP types, FRP thicknesses, and retrofitting modes. In view of broader application in the engineering practice, all the designed columns for this comparative study are of square section. Of all the investigated columns, $\mathrm{S}-1$ is a conventional RC column as a control member. Each column consists of a $300 \mathrm{~mm} \times 300 \mathrm{~mm}$ square cross section and a height of $3000 \mathrm{~mm}$. The columns are reinforced with four $20 \mathrm{~mm}$ longitudinal bars and $10 \mathrm{~mm}$ stirrups. As depicted in Figure 1, the reinforcement ratio is $1.4 \%$. The geometry and reinforcement of the $\mathrm{RC}$ column come from a column in the actual project, which is designed based on the Chinese code for concrete structures (GB50010-2010). The material properties for concrete and steel are obtained from the material test and are described in Table 1.

The retrofitted columns are designed from the following three aspects. Firstly, as the commonly used strengthening materials, CFRP, GFRP, AFRP are selected to be the retrofitting materials for comparative study. Table 2 lists the properties of the three types of FRP materials. The material properties are obtained from previous research on FRP retrofitting [13, 16, 22]. Secondly, the structures are often strengthened with multilayer FRP material in engineering reinforcement application. This study also investigates the effect of FRP 


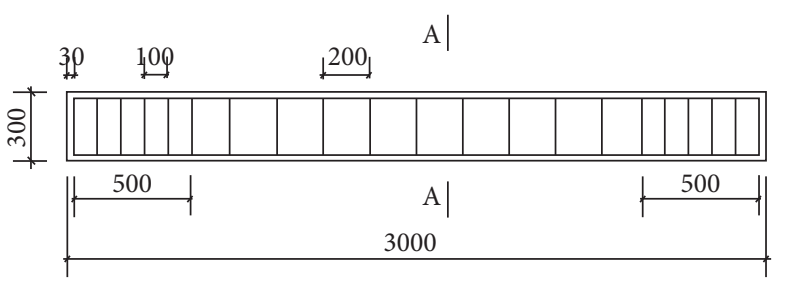

(a)

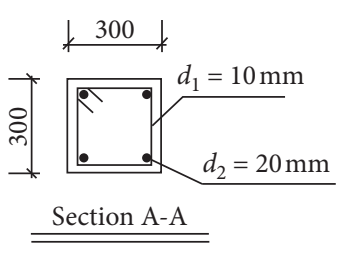

(b)

FIGURE 1: Geometry and reinforcement of the column. (a) Reinforcement configuration. (b) Cross section.

TABLE 1: Material properties for steel reinforcement and concrete.

\begin{tabular}{lcc}
\hline Material & Parameters & Magnitude \\
\hline \multirow{3}{*}{ Steel reinforcement } & Mass density & $7830 \mathrm{~kg} / \mathrm{m}^{3}$ \\
& Young's modulus & $208 \mathrm{GPa}$ \\
& Poisson's ratio & 0.3 \\
& Yield stress & $450 \mathrm{MPa}$ \\
\hline \multirow{3}{*}{ Concrete } & Mass density & $2400 \mathrm{~kg} / \mathrm{m}^{3}$ \\
& Compressive strength & $40 \mathrm{MPa}$ \\
& Shear modulus & $14.86 \mathrm{GPa}$ \\
\hline
\end{tabular}

thickness or layers on blast protection. The thicknesses of $0.17 \mathrm{~mm}, 0.34 \mathrm{~mm}, 0.51 \mathrm{~mm}, 0.68 \mathrm{~mm}$, and $0.85 \mathrm{~mm}$ (namely, 1 layer, 2 layers, 3 layers, 4 layers, and 5 layers) are considered. Thirdly, four retrofitting modes were designed in this study. Under blast loading, RC columns may suffer flexural damage, shear damage, and flexuralshear damage. The vulnerable parts are mainly concentrated in the middle and two ends of the column [23]. Among the four retrofitting modes shown in Figure 2, Mode A is the wholly FRP wrapped mode, and the others are partially wrapped modes. Mode B is $1800 \mathrm{~mm}$ length FRP wrapped at the midspan of the column. Mode $\mathrm{C}$ is every $600 \mathrm{~mm}$ FRP wrapped at both midspan and two ends of the column. Mode D is two $900 \mathrm{~mm}$ length FRP sheets wrapped at two ends of the column. The total length of FRP material used in the three partial retrofitting designs is $1800 \mathrm{~mm}$.

Each investigated column is given a specific number in this study so as to describe the columns in the following parts conveniently. Except the unretrofitted column S-1, all the retrofitted columns in this study are assigned as "XX-X." The first capital refers to the abbreviation of FRP type, the second capital is the retrofitting layer of FRP, and the last capital represents the retrofitting mode. For example, G3-C is the column retrofitted with 3-layer GFRP material and the retrofitting mode is Mode $\mathrm{C}$.

\section{Finite Element Model}

Numerical simulation is an effective approach to analyzing the blast response of structures. Some data and phenomena that are difficult to be observed from the experiment can be easily obtained in the numerical simulation. Moreover, this method can significantly save the research expenses. A wellknown explicit dynamic program, LS-DYNA, is adopted in numerical analysis.

\subsection{Material Model}

3.1.1. Steel Reinforcement Model. For the material model of both longitudinal bars and stirrups, kinematic hardening plasticity model is chosen to model the steel reinforcement. In LS-DYNA, this model is implemented as keyword MAT_PLASTIC_KINEMATIC (MAT003). The yield stress function of steel is given by

$$
\sigma_{y}=\left[1+\left(\frac{\dot{\varepsilon}}{C}\right)^{1 / p}\right]\left(\sigma_{0}+\beta E_{p} \varepsilon_{p}^{\text {eff }}\right)
$$

where $\sigma_{0}$ is the initial yield stress, $C$ and $p$ are strain rate parameters, $\beta$ is the hardening parameter, $\dot{\varepsilon}$ and $\varepsilon_{p}^{\mathrm{eff}}$ are strain rate and effective plastic strain, respectively, and $E_{p}$ is plasticity hardening modulus. As shown in Figure $3, E_{t}$ is the slope of the bilinear stress-strain curve, and $l$ and 10 are the undeformed and deformed lengths of uniaxial tension specimen. By varying the hardening parameter $\beta$, kinematic hardening, isotropic hardening, and combination hardening could be specified.

The strength of steel materials increases under the high strain rate impact. Based on the Cowper-Symonds model [24], the strain rate effect of steel reinforcement is considered as the dynamic increase factor (DIF) of $1+(\dot{\varepsilon} / C)^{1 / p}$. This material model is particularly suitable for modeling the dynamic behavior of steel under blast loading [25].

3.1.2. Concrete Model. Currently, the concrete material models that are commonly used in the impact issues mainly include the Johnson-Holmquist-Cook (JHC) model [26], Riedel-Hiermaier-Thoma (RHT) model [27], and Malvar model [28]. In this study, MAT_JOHNSON_HOLMQUIST_CONCRETE (MAT 111) in LS-DYNA is selected to model the concrete material. This model is applicable to simulate concrete under high pressure, high strain, and high strain rate [29]. The advantage of JHC model is the comprehensive consideration of stain rate effect and accumulated damage effect [30]. As depicted in Figure 4, the equivalent yield strength of the model is given by

$$
\sigma^{*}=\left[A(1-D)+B p^{* N}\right]\left[1+C \ln \left(\frac{\dot{\varepsilon}}{\dot{\varepsilon}_{0}}\right)\right],
$$

where $\sigma^{*}=\sigma / f_{c}^{\prime}$ denotes the normalized equivalent stress, in which $\sigma$ is the actual equivalent stress and $f_{c}^{\prime}$ is the quasistatic uniaxial compressive strength; $A$ represents the normalized cohesive strength; $B$ represents the normalized 
TABLE 2: Material properties for FRP.

\begin{tabular}{|c|c|c|c|}
\hline \multirow{2}{*}{ Parameters } & \multicolumn{3}{|c|}{ Magnitude } \\
\hline & CFRP & GFRP & AFRP \\
\hline Mass density & $1580 \mathrm{~kg} / \mathrm{m}^{3}$ & $1600 \mathrm{~kg} / \mathrm{m}^{3}$ & $1440 \mathrm{~kg} / \mathrm{m}^{3}$ \\
\hline Young's modulus-longitudinal direction & $138 \mathrm{GPa}$ & $75.6 \mathrm{GPa}$ & $67 \mathrm{GPa}$ \\
\hline Young's modulus-transverse direction & $9.65 \mathrm{GPa}$ & $17.7 \mathrm{GPa}$ & $4.7 \mathrm{GPa}$ \\
\hline Poisson's ratio & 0.021 & 0.025 & 0.028 \\
\hline Shear modulus & $5.24 \mathrm{GPa}$ & $2.8 \mathrm{GPa}$ & $2.0 \mathrm{GPa}$ \\
\hline Longitudinal tensile strength & $2280 \mathrm{MPa}$ & $1330 \mathrm{MPa}$ & $1420 \mathrm{MPa}$ \\
\hline Transverse tensile strength & $57 \mathrm{MPa}$ & $69 \mathrm{MPa}$ & $36 \mathrm{MPa}$ \\
\hline Shear strength & $71 \mathrm{MPa}$ & $70 \mathrm{MPa}$ & $53 \mathrm{MPa}$ \\
\hline
\end{tabular}

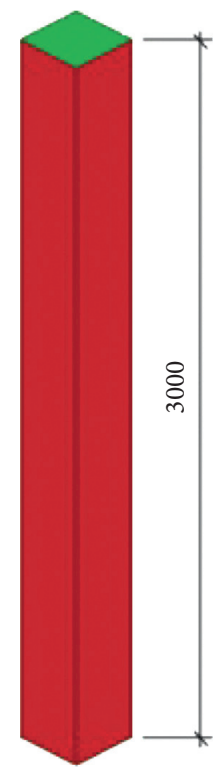

(a)

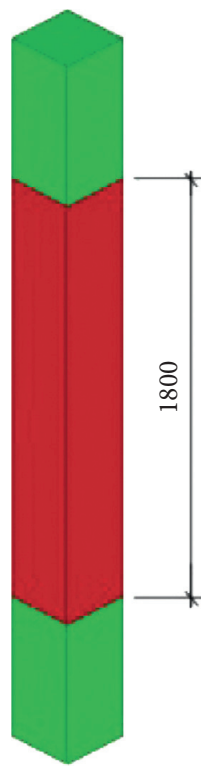

(b)

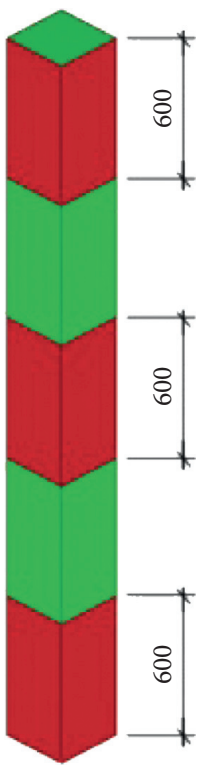

(c)

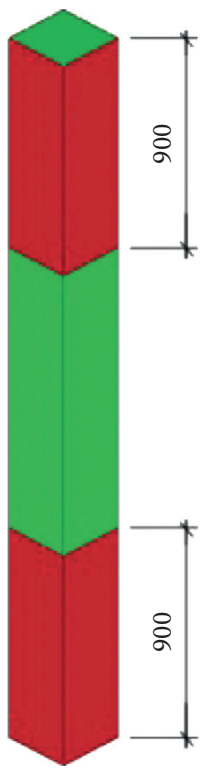

(d)

Figure 2: Four retrofitting modes. (a) Mode A. (b) Mode B. (c) Mode C. (d) Mode D.

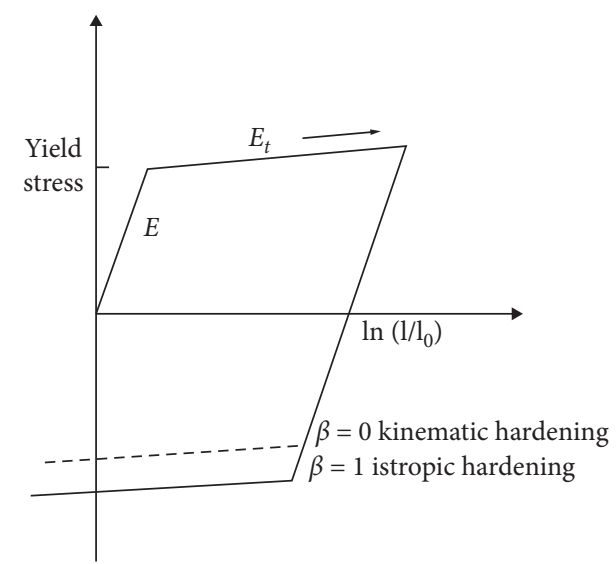

FIGURE 3: Stress-strain relationship of hardening material.

pressure hardening; $C$ represents the strain rate coefficient; $N$ represents the pressure hardening exponent; $p^{*}=p / f_{c}^{\prime}$ denotes the normalized pressure, in which $p$ is the hydrostatic pressure; $\dot{\varepsilon}$ and $\dot{\varepsilon}_{0}=1.0 \mathrm{~s}^{-1}$ are the strain rate and

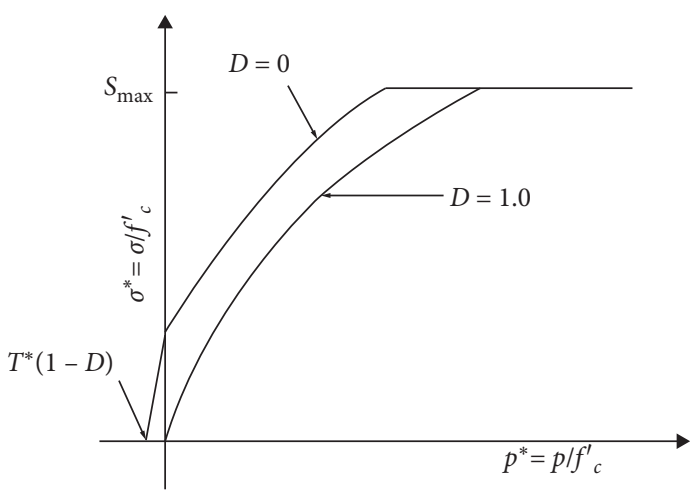

FIgURE 4: Constitutive law of JHC model.

reference strain rate, respectively; and $D(0 \leq D \leq 1)$ represents the damage parameter and is expressed as

$$
D=\sum \frac{\Delta \varepsilon_{p}+\Delta \mu_{p}}{D_{1}\left(p^{*}+T^{*}\right)^{D_{2}}},
$$


where $\Delta \varepsilon_{p}$ is the equivalent plastic strain increment and $\Delta \mu_{p}$ is the plastic volumetric strain increment; $T^{*}=T / f_{c}^{\prime}$ denotes the normalized largest tensile hydrostatic pressure, in which $T$ is the maximum tensile hydrostatic pressure; and $D_{1}$ and $\mathrm{D}_{2}$ are damage constants.

In JHC model, the relationship between pressure and volume is described as equation of state in three response regions as follows. The curve of hydrostatic pressure and volumetric strain is also illustrated in Figure 5.

$$
P=K \mu \text { (elastic region), }
$$

where $P$ is the hydrostatic pressure, $K$ is the elasticity modulus, and $\mu$ is volumetric strain.

$$
\left.P=\frac{P_{\text {crush }}+\left(\mu-\mu_{\text {crush }}\right)\left(P_{\text {lock }}-P_{\text {crush }}\right)}{\left(\mu_{\text {lock }}-\mu_{\text {crush }}\right)} \text { (plastic transition region }\right),
$$

where $P_{\text {crush }}$ and $\mu_{\text {crush }}$ are the crushed pressure and volumetric strain in the uniaxial compression test of concrete; $P_{\text {lock }}$ and $\mu_{\text {lock }}$ are the locking pressure and volumetric strain.

$$
P=K_{1} \bar{\mu}+K_{2} \bar{\mu}^{2}+K_{3} \bar{\mu}^{3} \text { (fully dense region), }
$$

where $\bar{\mu}=\left(\mu-\mu_{\text {lock }}\right) /\left(1+\mu_{\text {lock }}\right)$ is the modified volumetric strain; $K_{1}, K_{2}$, and $K_{3}$ are material constants.

\subsubsection{FRP Model. MAT_ENHANCED_COMPOSITE_-} DAMAGE (MAT054) in LS-DYNA is applied to model the behavior of FRP composite. This material model can effectively simulate the composite materials especially orthotropic materials. The failure criterion of this material model is based on Chang-Chang model. It includes the failure criteria for the tensile fiber mode, compressive fiber mode, tensile matrix mode, and compressive matrix mode [31]. The strength enhancement of FRP under high strain is relatively insignificant and negligible $[32,33]$, so the strain rate effect of CFRP is ignored in this study.

3.2. Mesh Size. The numerical results are affected by the mesh size especially when the nonlinear material models are adopted in simulation [34]. With a larger mesh size, the computing time is applicable while the accuracy of the results is lower. On the contrary, if the mesh size is too small, even though the computing accuracy is guaranteed, the computing efficiency is rather low. In order to ensure the efficiency and accuracy in numerical analysis, trial simulation tests were carried out with $10 \mathrm{~mm}$ being selected as the mesh size in this study. Moreover, the simulation converged well when the mesh size is $10 \mathrm{~mm}$.

3.3. Generation of Blast Loading. The press-time history curve of typical blast load is shown in Figure 6(a). $P_{O}$ is the initial atmospheric pressure. After detonation, the press of blast wave reaches the peak press $P_{S O}$ quickly at the time of $t_{A}$. Then the press drops gradually to the initial atmospheric press through the positive press duration $t_{0}$. During the time

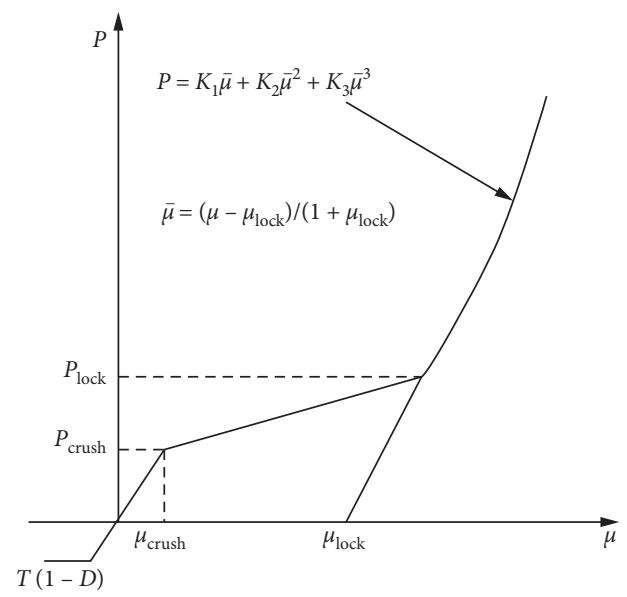

FIGURE 5: Relationship of hydrostatic pressure and volumetric strain in JHC model.

of $t_{0}^{-}$, the press keeps on decreasing to the peak value of $P_{S O}^{-}$ in the negative phase and then finally returns to the initial atmospheric pressure. In LS-DYNA, blast loading can be generated by three approaches. (1) As shown in Figure 6(b), the blast loading is simplified to triangle load by neglecting the negative phase of blast wave. The load curve is defined using the keyword LOAD_CURVE. This approach is quite easy to implement and high in computational efficiency, but the accuracy is relatively low due to the simplification of blast loading. (2) Another approach is to develop the model of air domain, explosive, and structures according to the actual geometry. The blast loading is generated by detonating the explosive using the keyword INITIAL_DETONATION. As to the numerical results of this approach, even the propagation of blast wave within the air is feasible to be observed. However, the computational amount is extremely large especially for a small mesh size or a large standoff distance case. (3) The third way is to utilize the built-in function CONWEP air blast model. CONWEP is an empirical blast function based on the data from various blast tests. By employing the keyword LOAD_BLAST and LOAD_SEGMENT_SET, the blast loading is generated. This blast function shows a high computational accuracy within an acceptable computational efficiency [35]. In this study, the blast loading is generated by CONWEP approach.

3.4. Boundary Conditions and Erosion. The reinforcement bars are modeled with beam elements, concrete is employed with solid elements, and FRP is adopted with shell elements. Separate model is utilized to develop the RC column wrapped with FRP. In order to be consistent with the fixed ends condition in the following blast tests, translational and rotational constraints for $x, y$, and $z$ directions are implemented at the head and the foot of the column using the keyword BOUNDARY_SPC_SET. Perfect bond is assumed in this study as the slip between concrete and rebar can be neglected under the instantaneous load [29]. In order to veritably simulate the crush and fracture of the concrete under impulsive loading, the erosion algorithm is employed. 


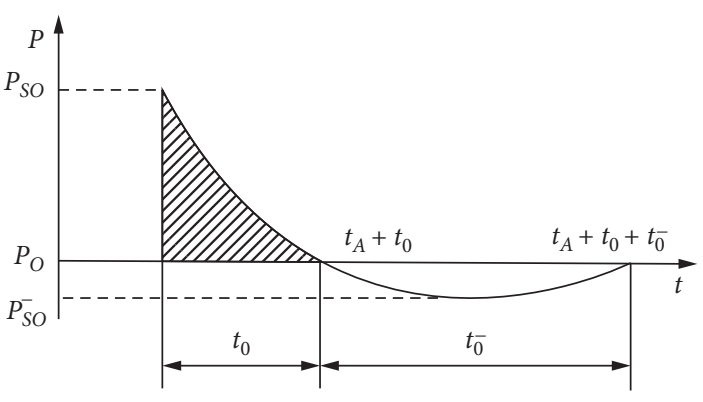

(a)

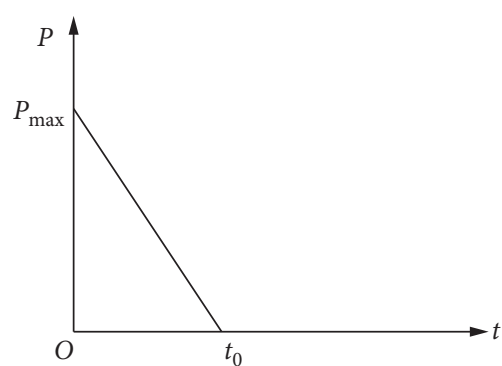

(b)

Figure 6: Press-time curve of blast loading. (a) Typical blast loading. (b) Simplified blast loading.

By adding the keyword MAT_ADD_EROSION, the elements in finite element model are deleted when the erosion criterion reaches the given value. In this study, a principle tensile strain of 0.001 is adopted for the primary criterion of concrete [36].

3.5. Verification of Numerical Modeling. The above-mentioned numerical modeling should be validated against the relevant blast tests. The test implemented in laboratory with simulated blast loading is inappropriate for verification because the strain rate of simulated blast loading is different from the stain of real blast loading in explosion. The available data are limited in the relevant blast test. In this paper, the finite element model is validated against the blast test of RC circular column retrofitted with CFRP carried out by Liu [20]. Since the specimens in blast test are circular columns while the investigated columns in this paper are square, the proposed numerical model was also compared with the numerical results of RC square column retrofitted with CFRP analyzed by Crawford [4].

The column in the field blast test was a circular section column with a diameter of $400 \mathrm{~mm}$ and a length of $3500 \mathrm{~mm}$. The concrete strength grade was $\mathrm{C} 40$ and the reinforcement ratio was $0.9 \%$. The column was wholly retrofitted with onelayer CFRP sheet. As to Case 26 in the blast test, the explosive was $2 \mathrm{~kg}$ TNT and was detonated at a standoff distance of $1500 \mathrm{~mm}$. The numerical model is generated by the proposed model mentioned above, and the geometry of column and material properties are in accordance with the blast test. Figure 7 displays finite element model of the RC column retrofitted with FRP after meshing. Since the field blast test was very dangerous, only limited data were observed in the test. The numerical results are compared with those available test data. The deformation of the column exported from numerical analysis is compared with the deformation observed from the test. It can be seen from Figure 8 that the column is almost intact from both test and numerical results, and no obvious rupture of FRP is noticed. That is because the scaled distance in this case is $1.5 \mathrm{~m} / \mathrm{kg}^{1 / 3}$, which is classified as far blast event. One acceleration sensor was set on the backside of the column with a height of $300 \mathrm{~mm}$. Figure 9 illustrates the comparison between the test result and numerical result on the acceleration history curve of the column. The comparison shows that the numerical result is essentially in agreement with the test result. As to Case 25 in the field test, the weight of TNT is $1 \mathrm{~kg}$, and the standoff distance between explosive and the column is still $1500 \mathrm{~mm}$. Two strain gauges were stuck at the longitudinal bar and stirrup separately with a height of $330 \mathrm{~mm}$. One pressure transducer was arranged at the height of $1330 \mathrm{~mm}$. Table 3 compares the numerical results and the data collected from the test. The deviation rate of the strain of longitudinal bar and stirrup is only $-4 \%$ and $-4.4 \%$. The numerical result is very close to the test data. The deviation rate of the arrival time of the peak pressure is $-10.19 \%$, and the deviation rate of the peak pressure is $-0.94 \%$. This is mainly because field blast tests are highly sensitive to the environment and other external factors. The actual environment of the test site cannot be completely simulated in the numerical analysis, but the deviation rate is still in a rational range.

Moreover, in order to verify the proposed numerical approach further, a finite element model is developed and compared with the results analyzed in [4]. The column is a square RC column with a section of $750 \mathrm{~mm} \times 750 \mathrm{~mm}$ and a height of $3650 \mathrm{~mm}$. Eight longitudinal bars with a diameter of $32 \mathrm{~mm}$ and stirrups with a diameter of $10 \mathrm{~mm}$ at $450 \mathrm{~mm}$ are reinforced. The reinforcements are ASTM A615 Grade 60 steel bars. The strength and elasticity modulus are $34.5 \mathrm{MPa}$ and $29 \mathrm{GPa}$, respectively. The RC column is retrofitted with six-layer CFRP sheets, and the total thickness of CFRP sheets is $0.5 \mathrm{~m}$. The finite element model is developed according to the approach proposed in this study. Table 4 compares the numerical results in this paper and those in [4]. Additionally, the displacement history curve at midspan of the column in Case 2 is compared in Figure 10.

From the above validation and comparison, the proposed finite element proved to be a reliable approach to simulate the performance of RC columns retrofitted with FRP under blast loading. In addition, the verified numerical model is suitable for evaluating the blast response of RC columns retrofitted with FRP in different blast situation or different retrofitting scheme.

\section{Results and Discussion}

Based on the verified finite element model, a series of RC columns retrofitted with different strategies are numerically analyzed. The details of the column and the design of retrofitting schemes are described in Section 2. The material 


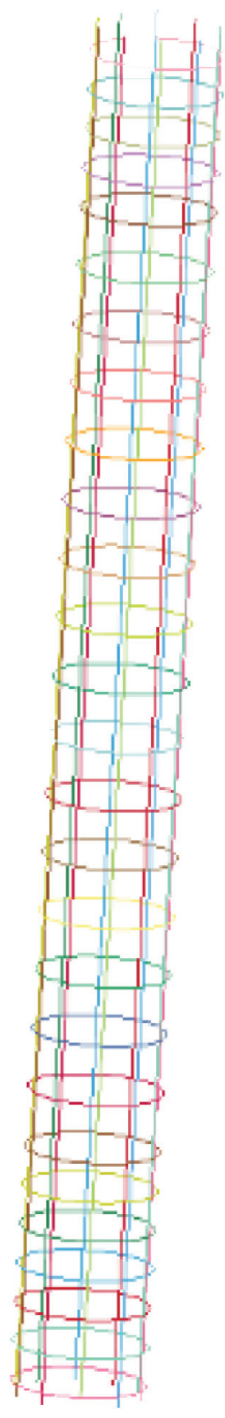

(a)

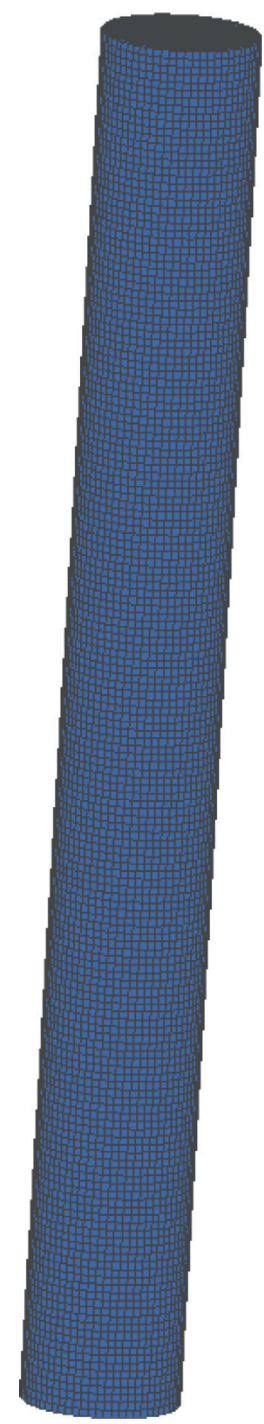

(b)

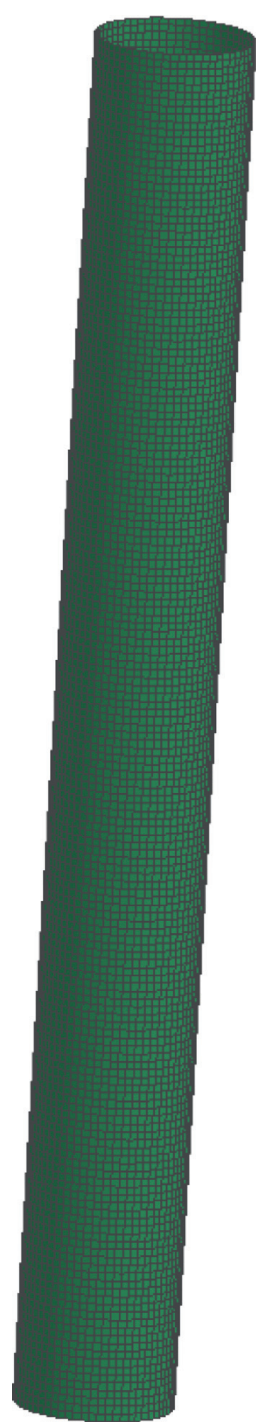

(c)

Figure 7: Finite element model of tested column. (a) Rebar. (b) Concrete. (c) FRP.

model and analysis setting of the investigated columns are developed based on Section 3. The explosives of all investigated cases are $8 \mathrm{~kg}$ TNT with a standoff distance of $0.8 \mathrm{~m}$, and the scaled distance is $0.4 \mathrm{~m} / \mathrm{kg}^{1 / 3}$. After being solved by LS-DYNA, the numerical results of the numerical models are postprocessed by LS-PrePost, and available data are exported.

Deformation is an important index to measure the blast resistance performance of the structural members. According to the numerical results, the columns mainly suffer flexural deformation. The maximum displacement occurs at the midspan of the member. Therefore, the displacements of midspan of the columns under blast loading are exported to measure the blast performance. Additionally, damage assessment is chosen to evaluate the damage degree of the structure. Based on the Unified Facilities Criteria (UFC 3-340-02), support rotation angle is usually used as a failure criterion for structural members. The support rotation angle is a combination of the maximum deflection of a given column and the length of the column. This angle is usually used in damage assessment of the structure under blast loading and blast resistance design. The support rotation angle $\theta$ is calculated by the maximum midspan deflection and half-span length, which is given by [37]

$$
\theta=\tan ^{-1}\left(\frac{2 x_{m}}{l}\right)
$$

where $x_{m}$ refers to the maximum displacement of the column and $l$ denotes the length of the column. According to the limited rotation values given by standards, the local damage level can be classified into three categories: (1) slight damage $\left(\theta<2^{\circ}\right)$; (2) moderate damage $\left(2^{\circ} \sim 4^{\circ}\right)$; (3) severe damage $\left(\theta>4^{\circ}\right)$ [38]. All the retrofitting schemes and main results of the investigated columns are listed in Table 5.

The mass of explosive in the numerical analysis is relatively small, and the scaled distance is $0.4 \mathrm{~m} / \mathrm{kg}^{1 / 3}$. The blast 


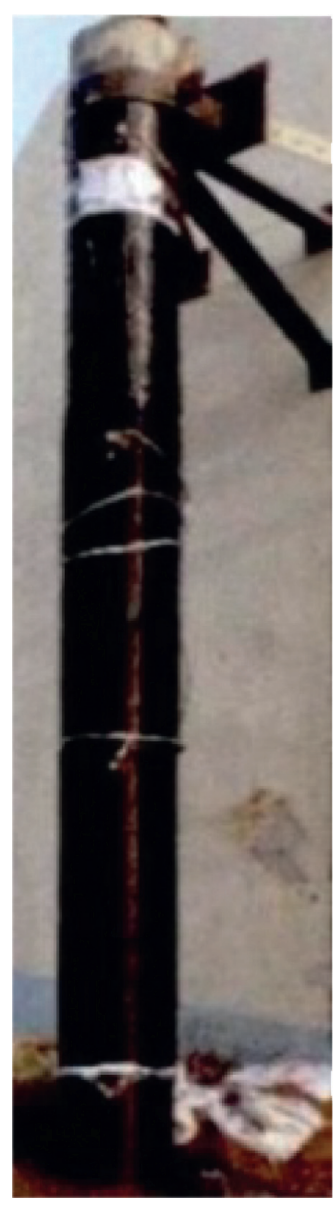

(a)

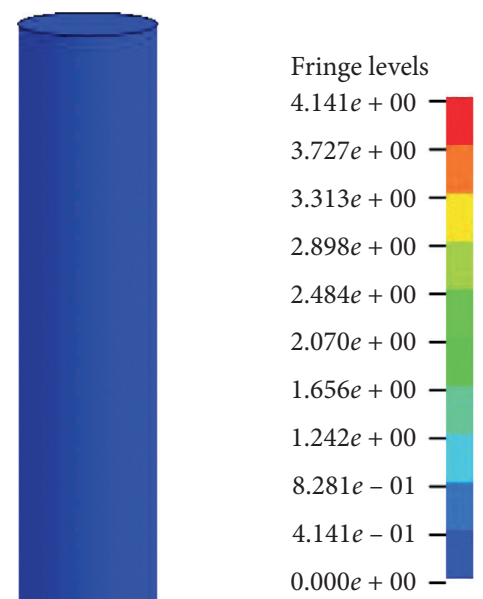

(b)

Figure 8: Deformation of tested column. (a) Test result. (b) Numerical result.

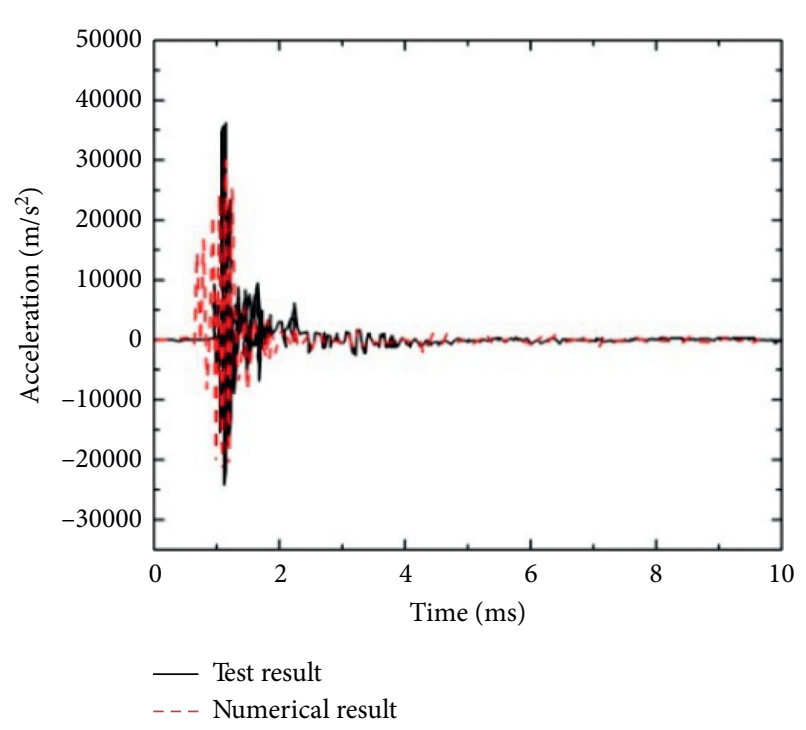

FIGURE 9: Acceleration history curve of the test point on the column.

event is identified as the intermediate class, so the given columns all suffer slight damage based on the results of support rotation angle. As a whole, the retrofitting of FRP
TABLE 3: Comparison of numerical results and test data.

\begin{tabular}{lccc}
\hline & Test & Simulation & Deviation rate (\%) \\
\hline $\begin{array}{l}\text { Strain of longitudinal } \\
\text { bar }\end{array}$ & $150 \mu \varepsilon$ & $144 \mu \varepsilon$ & -4.0 \\
$\begin{array}{l}\text { Strain of stirrup } \\
\text { Arrival time of peak }\end{array}$ & $273 \mu \varepsilon$ & $261 \mu \varepsilon$ & -4.4 \\
pressure & $2.56 \mathrm{~ms}$ & $2.299 \mathrm{~ms}$ & -10.19 \\
Peak pressure & $0.32 \mathrm{MPa}$ & $0.317 \mathrm{MPa}$ & -0.94 \\
\hline
\end{tabular}

material can reduce the deformation and damage of the columns under blast loading. However, under the same blast condition, the dynamic responses of columns retrofitted with different strategies are not uniform. It is necessary to find out the effect of different retrofitting strategies on blast mitigation. The details are discussed from the following aspects.

4.1. FRP Thickness. The RC columns retrofitted with different thicknesses of FRP were initially reported to simulate the blast resistance of RC columns retrofitted with different layers of FRP material. Figure 11 describes the displacement history curve at midspan of columns retrofitted with different thicknesses of FRP. In columns wholly retrofitted with CFRP, for 
TABLE 4: Comparison of the maximum deflection in the analysis.

\begin{tabular}{|c|c|c|c|c|c|}
\hline \multirow{2}{*}{ Case } & \multirow{2}{*}{ Charge weight $(\mathrm{kg})$} & \multirow{2}{*}{ Standoff distance $(\mathrm{m})$} & \multicolumn{2}{|c|}{ Maximum deflection $(\mathrm{mm})$} & \multirow{2}{*}{ Deviation rate $(\%)$} \\
\hline & & & Crawford et al. [4] & Present analysis & \\
\hline 1 & 682 & 3.05 & 132 & 146.25 & 10.80 \\
\hline 2 & 682 & 3.05 & 18 & 19.13 & 6.28 \\
\hline 3 & 1364 & 6.1 & 88 & 91.47 & 3.94 \\
\hline
\end{tabular}

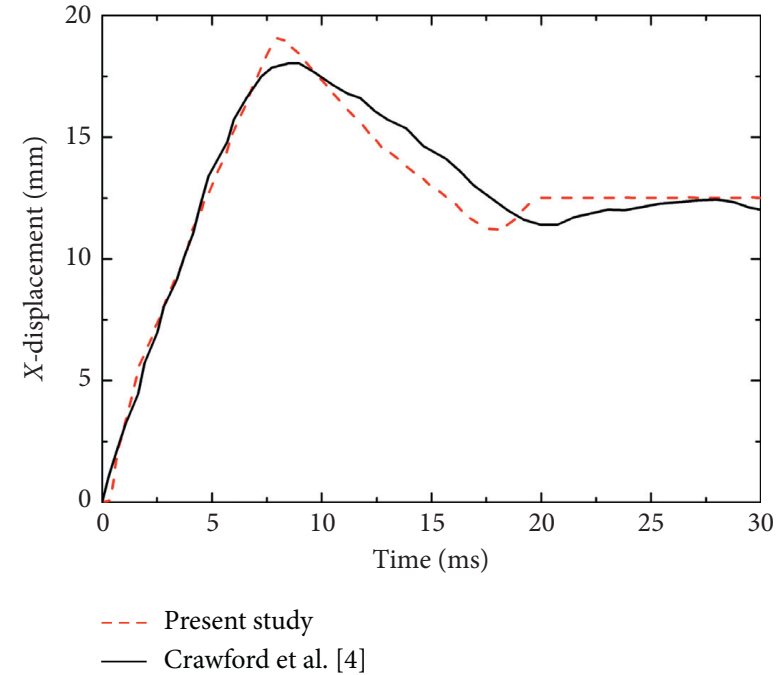

FIGURe 10: Displacement history curve at midspan of the column in Case 2.

example, when the thickness of CFRP is $0.17 \mathrm{~mm}, 0.34 \mathrm{~mm}$, $0.51 \mathrm{~mm}, 0.68 \mathrm{~mm}$, and $0.85 \mathrm{~mm}$ (namely $1,2,3,4$, and 5 layers, respectively), the maximum deflection of the column is $28.56 \mathrm{~mm}, 23.91 \mathrm{~mm}, 20.79 \mathrm{~mm}, 18.08 \mathrm{~mm}$, and $17.90 \mathrm{~mm}$. The deformation reduced obviously compared with the unretrofitted column. The blast resistance performance improves with the increase of FRP thickness. Compared with $S-1$, the maximum displacement of C1-A, C2-A, C3-4, C4-A, and C5-A reduces by $22.20 \%, 34.86 \%, 43.37 \%, 50.75 \%$, and $51.24 \%$, respectively. It should be noticed that the decrease does not present a linear change. Instead, the blast mitigation effect weakens with the increase of FRP thickness or layers. When the FRP thickness reaches a certain value, it is of little significance to further increase the thickness of FRP for blast protection. The deformations of C4-A and C5-A are very approximate. In these cases, if the thickness of FRP is above $0.68 \mathrm{~mm}$ (4 layers), the retrofitting scheme is uneconomical. Columns retrofitted with AFRP and GFRP exhibit the same pattern as columns retrofitted with CFRP.

4.2. FRP Type. The blast responses of RC columns retrofitted with different types of FRP material were also studied. For expressing the blast mitigation effect of FRP materials, the unretrofitted column S-1 was also included in the comparative study. Figure 12 shows the deformation and damage distribution of S-1, A1-A, C1-A, and G1-A. As can be seen from Figure 12(a), since the midspan of the column S-1 is closest to the explosive, obvious crushing damage of concrete at the midspan can be found. With the propagation of blast wave, local concrete at the back surface of the column dilates and spalls. Cracks can also be observed at the top and bottom of the column due to the increase of the shear stress. Some of the longitudinal bars and stirrups slightly bend without any breakage. The maximum effective stress of the reinforcement at the midspan of the column is $512 \mathrm{MPa}$, which exceeds the yield stress of the steel reinforcement. For the retrofitted columns, the damage modes of the retrofitted column are quite different from that of conventional RC column. Minor cracks and no obvious spall phenomenon of the concrete can be observed. Partial ruptures of the FRP are noticed at two ends of the column. However, the wrapping of FRP can efficiently prevent the spalling and splashing of the concrete. Additionally, the bending deformations of the retrofitted columns are smaller than that of S-1. For the structural members that are not severely damaged, the deformation of the column is an important indicator to evaluate their blast resistance. The displacement history curves of midspan of S-1, A1-A, C1-A, and G1-A are illustrated in Figure 13. Under the blast loading, the deformations of all columns reach the peak rapidly and then drop to a certain value. The maximum deformation of $\mathrm{S}-1, \mathrm{~A} 1-\mathrm{A}$, $\mathrm{C} 1-\mathrm{A}$, and $\mathrm{G} 1-\mathrm{A}$ is $36.71 \mathrm{~mm}, 33.82 \mathrm{~mm}, 28.56 \mathrm{~mm}$, and $31.73 \mathrm{~mm}$, respectively. Compared with S-1, the deflection of $\mathrm{A} 1-\mathrm{A}, \mathrm{C} 1-\mathrm{A}$, and G1-A reduces by $7.87 \%, 22.20 \%$, and $13.57 \%$. The FRP material effectively restrains the lateral expansion of the concrete inside, so that the concrete is under three-dimensional compression. Thus, the deformation performance of the column is enhanced, and the blast resistance is improved. Among the three types of FRP materials mentioned in this study, the deflection of the column retrofitted with CFRP is relatively the least. This indicates that CFRP is the best retrofitting material for blast protection. However, from an economic perspective, CFRP is the most expensive among the three materials. If the cost of retrofitting is considered, GFRP is a preferable choice because its cost is almost $1 / 4$ that of CFRP. For example, the maximum displacement of G2-A and C1-A is 26.93 and 28.56 , respectively. It can be noticed that the G2-A has better blast resistance effect and less cost than C1-A.

\subsection{Retrofitting Mode}

4.3.1. Dynamic Response. In addition to full FRP retrofitting, three local retrofitting methods are also designed in this paper. The details of the four retrofitting strategies are described in Section 2. Figure 14 shows the deflection-history curves of one-layer FRP-retrofitted column with different strengthening modes. The variation tendency of the deflection of the columns with time is basically the same. The 
TABLE 5: Information and main results of investigated columns.

\begin{tabular}{|c|c|c|c|c|c|}
\hline Column no. & FRP type & FRP thickness (mm) & Retrofitting mode & Max deflection (mm) & $\theta\left({ }^{\circ}\right)$ \\
\hline$S-1$ & - & - & - & 36.71 & 1.40 \\
\hline C1-A & CFRP & 0.17 & Mode A & 28.56 & 1.09 \\
\hline C1-B & CFRP & 0.17 & Mode B & 31.57 & 1.21 \\
\hline $\mathrm{C} 1-\mathrm{C}$ & CFRP & 0.17 & Mode C & 31.09 & 1.19 \\
\hline C1-D & CFRP & 0.17 & Mode D & 32.44 & 1.24 \\
\hline $\mathrm{C} 2-\mathrm{A}$ & CFRP & 0.34 & Mode A & 23.91 & 0.91 \\
\hline C3-A & CFRP & 0.51 & Mode A & 20.79 & 0.79 \\
\hline $\mathrm{C} 3-\mathrm{B}$ & CFRP & 0.51 & Mode B & 23.17 & 0.88 \\
\hline $\mathrm{C} 3-\mathrm{C}$ & CFRP & 0.51 & Mode C & 22.93 & 0.88 \\
\hline C3-D & CFRP & 0.51 & Mode D & 23.85 & 0.91 \\
\hline C4-A & CFRP & 0.68 & Mode A & 18.08 & 0.69 \\
\hline C5-A & CFRP & 0.85 & Mode A & 17.90 & 0.68 \\
\hline A1-A & AFRP & 0.17 & Mode A & 33.82 & 1.29 \\
\hline A1-B & AFRP & 0.17 & Mode B & 35.74 & 1.36 \\
\hline A1-C & AFRP & 0.17 & Mode C & 35.13 & 1.34 \\
\hline A1-D & AFRP & 0.17 & Mode D & 35.96 & 1.37 \\
\hline A2-A & AFRP & 0.34 & Mode A & 29.55 & 1.13 \\
\hline A3-A & AFRP & 0.51 & Mode A & 25.76 & 0.98 \\
\hline A3-B & AFRP & 0.51 & Mode B & 27.69 & 1.06 \\
\hline A3-C & AFRP & 0.51 & Mode C & 27.03 & 1.03 \\
\hline A3-D & AFRP & 0.51 & Mode D & 28.04 & 1.07 \\
\hline A4-A & AFRP & 0.68 & Mode A & 22.79 & 0.87 \\
\hline A5-A & AFRP & 0.85 & Mode A & 22.03 & 0.84 \\
\hline G1-A & GFRP & 0.17 & Mode A & 31.73 & 1.21 \\
\hline G1-B & GFRP & 0.17 & Mode B & 34.61 & 1.32 \\
\hline G1-C & GFRP & 0.17 & Mode C & 34.15 & 1.30 \\
\hline G1-D & GFRP & 0.17 & Mode D & 35.12 & 1.34 \\
\hline G2-A & GFRP & 0.34 & Mode A & 26.93 & 1.03 \\
\hline G3-A & GFRP & 0.51 & Mode A & 23.11 & 0.88 \\
\hline G3-B & GFRP & 0.51 & Mode B & 24.98 & 0.95 \\
\hline G3-C & GFRP & 0.51 & Mode C & 24.27 & 0.93 \\
\hline G3-D & GFRP & 0.51 & Mode D & 25.86 & 0.99 \\
\hline G4-A & GFRP & 0.68 & Mode A & 20.92 & 0.80 \\
\hline G5-A & GFRP & 0.85 & Mode A & 20.38 & 0.78 \\
\hline
\end{tabular}

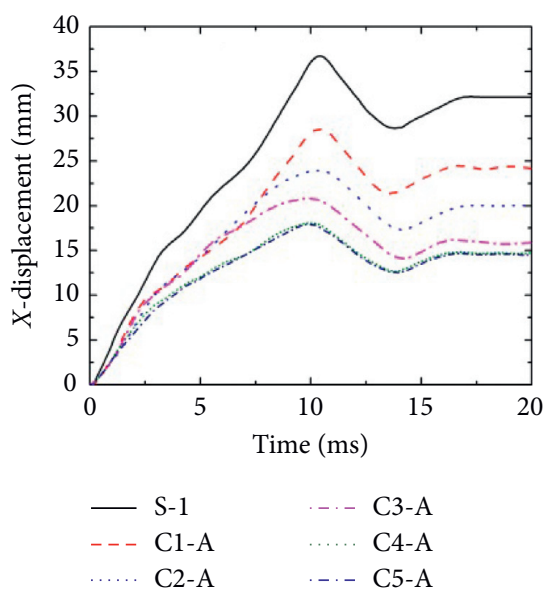

(a)

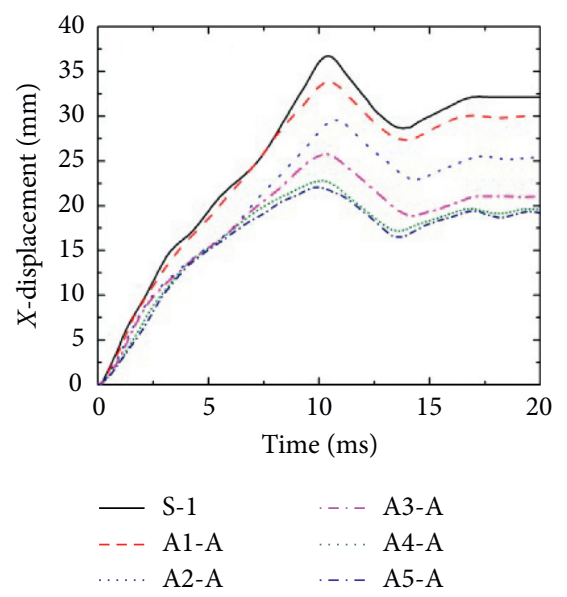

(b)
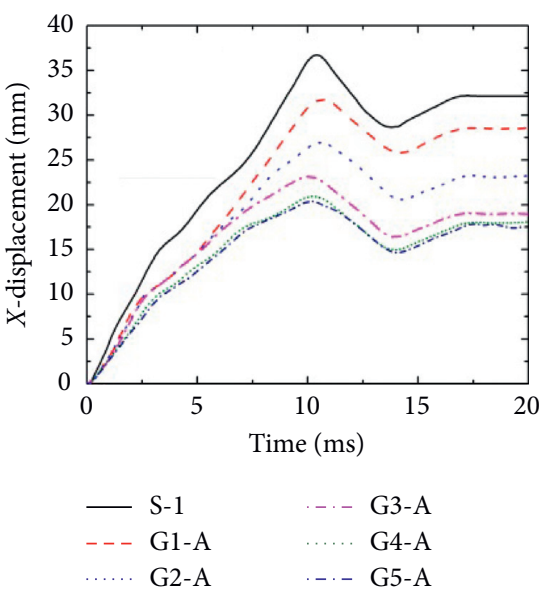

(c)

FIGURE 11: Displacement history curve at midspan of the column retrofitted with different FRP thicknesses. (a) CFRP. (b) AFRP. (c) GFRP.

maximum displacement at the midspan of the column is also used as a comparison indicator. For the one-layer CFRP-retrofitted columns, the maximum displacement of C1-A, C1-B, C1-C, and C1-D is $28.56 \mathrm{~mm}, 31.57 \mathrm{~mm}$,
$31.09 \mathrm{~mm}$, and $32.44 \mathrm{~mm}$, respectively. Compared with unretrofitted column S-1, the deflection of the abovementioned four columns reduces by $22.20 \%, 14.00 \%$, $15.31 \%$, and $11.63 \%$, respectively. For the one-layer AFRP- 


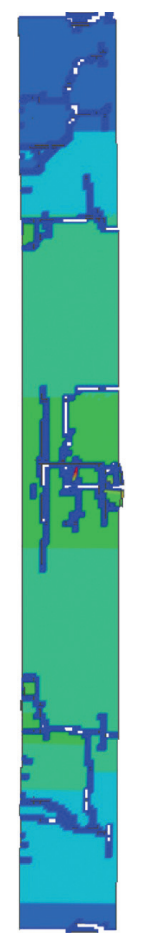

(a)

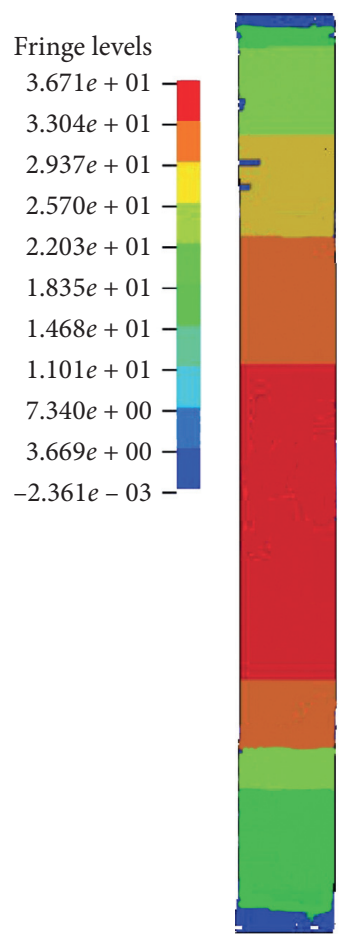

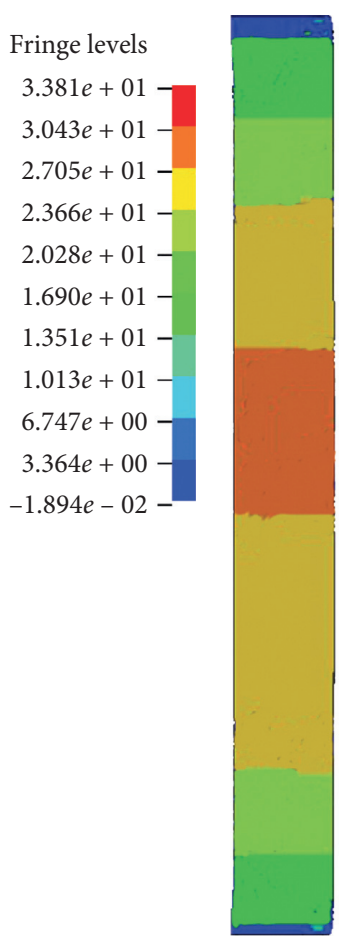

(b)
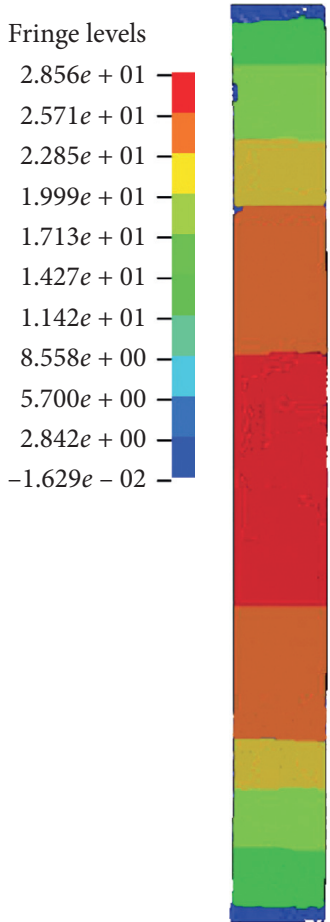

(c)
Fringe levels

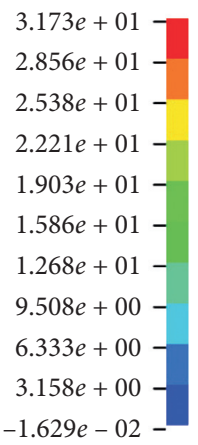

(d)

FIGURE 12: Damage distribution of columns retrofitted with different types of FRP (left view). (a) S-1. (b) A1-A. (c) C1-A. (d) G1-A.

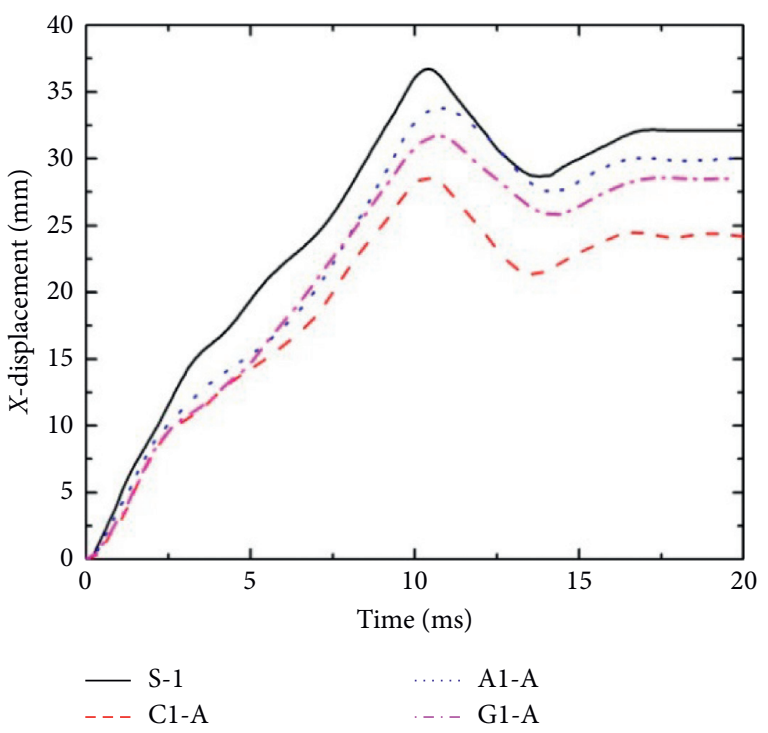

FIGURE 13: Displacement history curve at midspan of the column retrofitted with different FRP types.

retrofitted columns, the maximum deflection of A1-A, A1-B, $\mathrm{A} 1-\mathrm{C}$, and $\mathrm{A} 1-\mathrm{D}$ is $33.82 \mathrm{~mm}, 35.74 \mathrm{~mm}, 35.13 \mathrm{~mm}$, and $35.96 \mathrm{~mm}$, respectively. Compared with the maximum deflection of S-1, the deflection of the four columns decreases by $7.87 \%, 2.64 \%, 4.30 \%$, and $0.68 \%$, respectively. It is found that retrofitting the column with one-layer AFRP at two ends of the column has little effect on blast mitigation. For the one-layer GFRP-retrofitted columns, the maximum deflection of G1-A, G1-B, G1-C, and G1-D reduces by $13.57 \%$,
$5.72 \%, 6.97 \%$, and $4.33 \%$, respectively, compared with that of S-1. Figure 15 illustrates a comparison of the maximum deflection of columns retrofitted with different modes. No matter what the type of the FRP is and how many FRP layers are there, the effects of different retrofitting modes on blast mitigation are almost the same. For the performance of the column to resist deformation under blast loading, the wholly retrofitting mode is still the most effective strategy, while the effect of only two-end retrofitting mode is relatively the worst. The effects of Mode B and Mode C are close to each other in terms of maximum displacement and residual displacement. For the columns retrofitted with the same FRP material and thickness, the antiexplosion performance of wholly retrofitted column is better than that of locally retrofitted columns. Moreover, the protection of FRP wraps could mitigate the spalling of the inner concrete. However, the amount of FRP sheets used for local retrofitting is $60 \%$ of the amount of FRP materials used for full retrofitting in this paper. The method of partial retrofitting at middle and two ends of the column has also a good effect on lessening the deformation of RC columns under blast loading. Therefore, if the structure is inconvenient for whole retrofitting, it is recommended to apply this retrofitting strategy.

4.3.2. Retrofitting Length. According to the above research, Mode $\mathrm{C}$ exhibits the best blast resistance performance among all partial retrofitting modes. In Mode $\mathrm{C}$, the influence of retrofitting length on blast mitigation is further studied. As can be seen from Figure 16, in addition to the above retrofitting length of $600 \mathrm{~mm}$ for each section, numerical modes of 


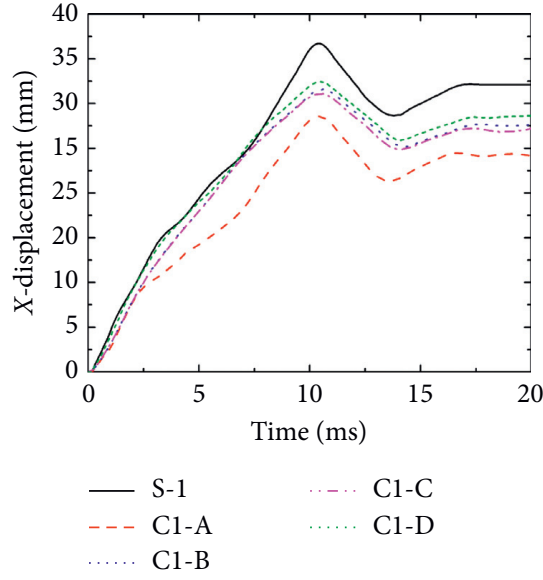

(a)

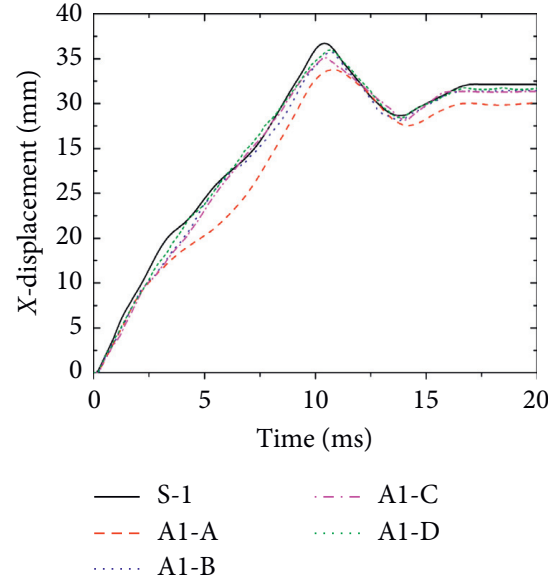

(b)
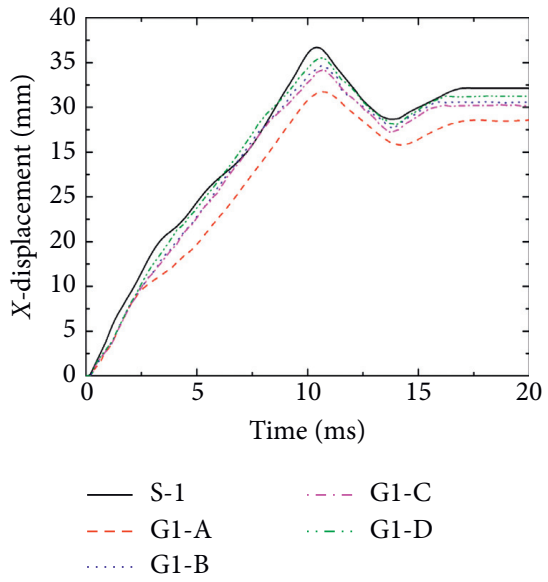

(c)

FIGURE 14: Displacement history curve at midspan of the columns retrofitted with different modes. (a) CFRP. (b) AFRP. (c) GFRP.

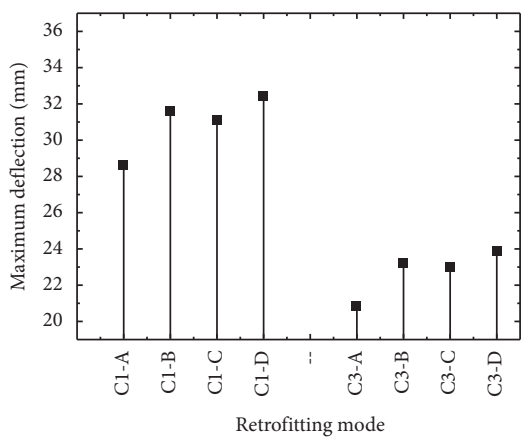

(a)

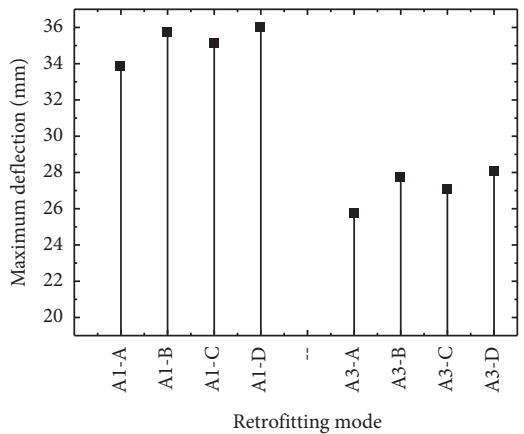

(b)

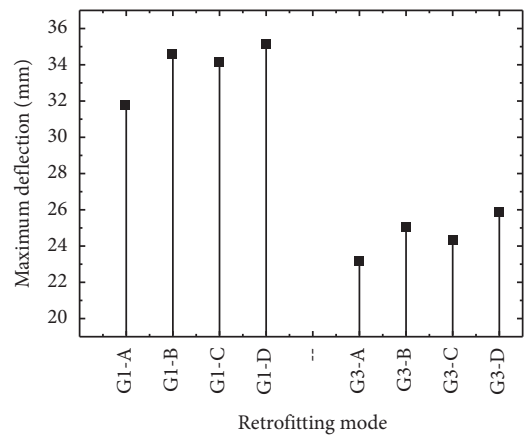

(c)

FIgURE 15: Maximum deflection of the columns retrofitted with different modes. (a) CFRP. (b) AFRP. (c) GFRP.

$300 \mathrm{~mm}, 400 \mathrm{~mm}, 500 \mathrm{~mm}, 700 \mathrm{~mm}, 800 \mathrm{~mm}$, and $900 \mathrm{~mm}$ for each section are developed. The dynamic responses of these columns under the same blast condition are investigated. Figure 17 depicts the maximum displacement of columns retrofitted with different retrofitting lengths in Mode C. The deformation becomes smaller under blast loading with the longer retrofitting length and larger wrapping area. With the increase of retrofitting length, the stiffness of the column increases, but the improvement for blast resistance does not show a linear relationship with the increase of retrofitting length. Similar to the phenomenon studied in FRP thickness, the growth rate of the blast mitigation effect slows down gradually when the length reaches a certain value. In this case, $400 \sim 700 \mathrm{~mm}$ for each section is deemed as the proper retrofitting length range for Mode $\mathrm{C}$.

\section{Conclusions}

In this paper, the dynamic response of reinforced concrete columns retrofitted with FRP is investigated using the numerical analysis approach. The main findings are summarized as follows.

(i) A finite element model of RC columns retrofitted with FRP under blast loading is developed. The strain rate effect of concrete and steel and orthotropic property of FRP material are considered in the finite element model. The proposed model is validated against the relevant test data. The numerical analysis corresponds well with the previous results.

(ii) A series of RC columns retrofitted with FRP are numerically analyzed using this reliable finite element model. The retrofitted columns are designed with different FRP types, FRP thicknesses, and retrofitting modes. Compared with conventional RC column, retrofitting with FRP can effectively mitigate the damage and deformation of the columns under blast loading.

(iii) The deformation of the column decreases with the increase of FRP thickness, but not in the same proportion. The blast mitigation effect weakens with the increase of the FRP material. In the investigated cases, when the thickness of FRP is above $0.68 \mathrm{~mm}$, adding the thickness of FRP has little effect in terms of improving the blast resistance of the column. Thus the maximum thickness for FRP retrofitting suggested in this study is $0.68 \mathrm{~mm}$ (namely, 4 layers). 


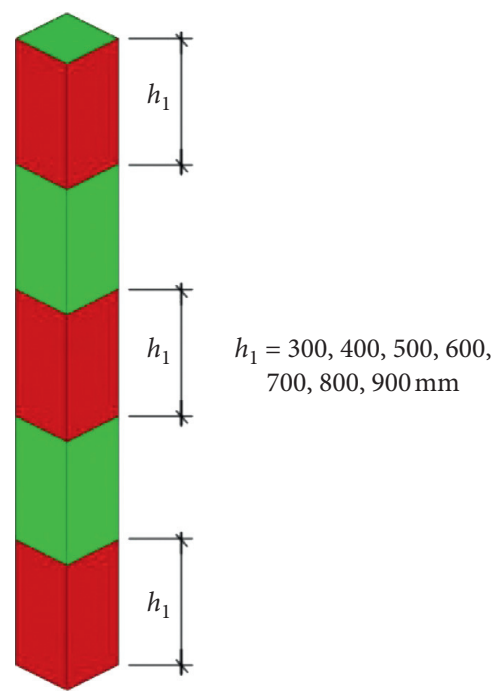

Figure 16: Design of retrofitting length.

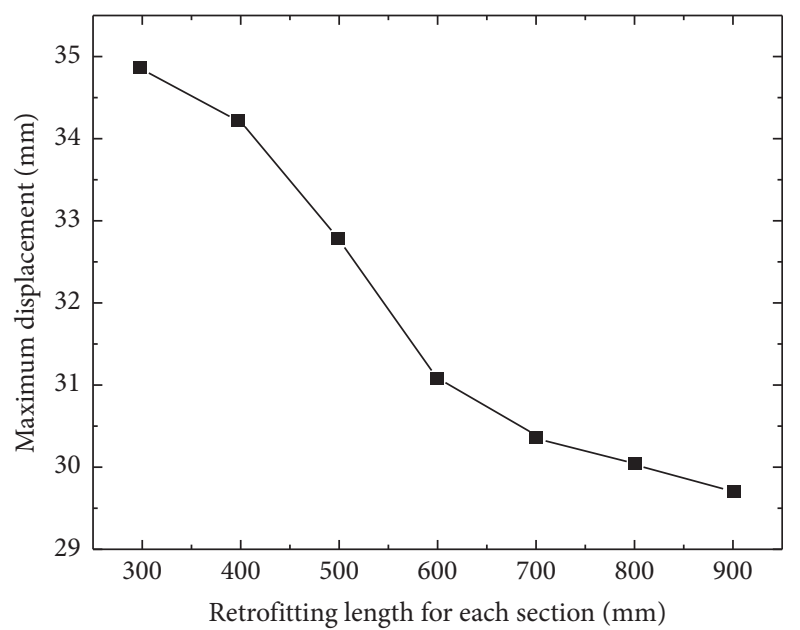

Figure 17: Maximum displacement of columns retrofitted with different retrofitting lengths.

(iv) In the three FRP types studied, CFRP is the best retrofitting material for improving the blast resistance of RC columns. GFRP is recommended as the retrofitting material if the cost of material is considered.

(v) A full retrofitting mode and three local retrofitting modes are designed in this study. The full retrofitting mode performs the best in terms of blast mitigation while the material amount is more than others. Among the three local retrofitting modes, retrofitting at both two ends and middle part of the column is suggested. $400 \sim 700 \mathrm{~mm}$ retrofitting length for each section is regarded as the proper length for this retrofitting mode.

\section{Data Availability}

The data used to support the findings of this study are available from the corresponding author upon request.

\section{Conflicts of Interest}

The authors declare that they have no conflicts of interest regarding the publication of this paper.

\section{Acknowledgments}

This study was financially supported by the National Natural Science Foundation of China (NSFC) (Grant no. 51878056), the Social Development Foundation for Science and Technology Planning Project of Shaanxi Province (Grant no. 2019SF-256), and the Fundamental Research Funds for the Central Universities, CHD (Grant nos. 300102280203 and 300102289105).

\section{References}

[1] L. Chen, Q. Fang, J. Fan, Y. Zhang, H. Hao, and J. Liu, "Responses of masonry infill walls retrofitted with CFRP, steel wire mesh and laminated bars to blast loadings," Advances in Structural Engineering, vol. 17, no. 6, pp. 817-836, 2014.

[2] H. Draganić, G. Gazić, and D. Varevac, "Experimental investigation of design and retrofit methods for blast load mitigation-a state-of-the-art review," Engineering Structures, vol. 190, pp. 189-209, 2019.

[3] L. V. D. Einde, L. Zhao, and F. Seible, "Use of FRP composites in civil structural applications," Construction and Building Materials, vol. 17, no. 6, pp. 389-403, 2007.

[4] J. E. Crawford, L. J. Malvar, J. W. Wesevich, J. Valancius, and A. D. Reynolds, "Retrofit of reinforced concrete structures to resist blast effects," ACI Structural Journal, vol. 94, no. 4, pp. 371-377, 1997.

[5] L. J. Malvar, K. B. Morrill, and J. E. Crawford, "Numerical modeling of concrete confined by fiber-reinforced composites," Journal of Composites for Construction, vol. 8, no. 4, pp. 315-322, 2004.

[6] L. J. Malvar, J. E. Crawford, and K. B. Morrill, "Use of composites to resist blast," Journal of Composites for Construction, vol. 11, no. 6, pp. 601-610, 2007.

[7] P. A. Buchan and J. F. Chen, "Blast resistance of FRP composites and polymer strengthened concrete and masonry structures-a state-of-the-art review," Composites Part B: Engineering, vol. 38, no. 5-6, pp. 509-522, 2007.

[8] J. H. Zhao, J. Dong, and D. F. Zhang, "Research status of dynamic responses of RC structure confined with FRP under blast loading," World Earthquake Engineering, vol. 35, no. 1, pp. 97-109, 2019.

[9] P. F. Silva and B. Lu, "Improving the blast resistance capacity of RC slabs with innovative composite materials," Composites Part B: Engineering, vol. 38, no. 5-6, pp. 523-534, 2007.

[10] J.-W. Nam, H.-J. Kim, S.-B. Kim, N.-H. Yi, and J.-H. J. Kim, "Numerical evaluation of the retrofit effectiveness for GFRP retrofitted concrete slab subjected to blast pressure," Composite Structures, vol. 92, no. 5, pp. 1212-1222, 2010.

[11] J.-W. Nam, I.-S. Yoon, and S.-T. Yi, "Numerical evaluation of FRP composite retrofitted reinforced concrete wall subjected to blast load," Computers and Concrete, vol. 17, no. 2, pp. 215-225, 2016.

[12] G. Tanapornraweekit, N. Haritos, P. Mendis, and T. Ngo, "Finite element simulation of FRP strengthened reinforced concrete slabs under two independent air blasts," International Journal of Protective Structures, vol. 1, no. 4, pp. 469488,2010 . 
[13] G. Tanapornraweekit, N. Haritos, and P. Mendis, "Behavior of FRP-RC slabs under multiple independent air blasts," Journal of Performance of Constructed Facilities, vol. 25, no. 5, pp. 433-440, 2011.

[14] X. S. Lin and Y. X. Zhang, "Nonlinear finite element analysis of FRP-strengthened reinforced concrete panels under blast loading," International Journal of Computational Methods, vol. 13, no. 4, Article ID 1641002, 2016.

[15] X. Kong, X. Qi, Y. Gu, I. A. Lawan, and Y. Qu, "Numerical evaluation of blast resistance of RC slab strengthened with AFRP," Construction and Building Materials, vol. 178, pp. 244-253, 2018.

[16] A. A. Mutalib and H. Hao, "Development of P-I diagrams for FRP strengthened RC columns," International Journal of Impact Engineering, vol. 38, no. 5, pp. 290-304, 2011.

[17] T. Rodriguez-Nikl, C.-S. Lee, G. A. Hegemier, and F. Seible, "Experimental performance of concrete columns with composite jackets under blast loading," Journal of Structural Engineering, vol. 138, no. 1, pp. 81-89, 2012.

[18] E. Jacques, A. Lloyd, P. Imbeau et al., "GFRP-Retrofitted reinforced concrete columns subjected to simulated blast loading," Journal of Structural Engineering, vol. 141, no. 11, Article ID 04015028, 2015.

[19] Y. Qasrawi, P. J. Heffernan, and A. Fam, "Performance of concrete-filled FRP tubes under field close-in blast loading," Journal of Composites for Construction, vol. 19, no. 4, Article ID 04014067, 2015.

[20] L. Liu, "Experimental study of differently protective RC piers under blast loading," Master Thesis, Southeast University, Nanjing, China, 2016.

[21] L. Liu, Z. H. Zong, C. Gao, S. Yuan, and F. Lou, "Experimental and numerical study of CFRP protective RC piers under contact explosion," Composite Structures, vol. 234, Article ID 111658, 2020.

[22] L. Yang, Y. Yan, and N. Kuang, "Experimental and numerical investigation of aramid fibre reinforced laminates subjected to low velocity impact," Polymer Testing, vol. 32, no. 7, pp. 1163-1173, 2013.

[23] Y. Shi, H. Hao, and Z.-X. Li, "Numerical derivation of pressure-impulse diagrams for prediction of RC column damage to blast loads," International Journal of Impact Engineering, vol. 35, no. 11, pp. 1213-1227, 2008.

[24] G. R. Cowper and P. S. Symonds, Strain Hardening and Strain Rate Effect in the Impact Loading of Cantilever Beams, Report in Brown University, Providence, RI, USA, 1957.

[25] X. Lin, Y. X. Zhang, and P. J. Hazell, "Modelling the response of reinforced concrete panels under blast loading," Materials \& Design (1980-2015), vol. 56, pp. 620-628, 2014.

[26] T. J. Holmoquist, G. R. Joshson, and W. H. Cook, "A computational constitutive model for concrete subjected to large strains, high strain rates, and high pressure," in Proceedings of the 14th International Symposium on Ballistics, Quebec, Canada, September 1993.

[27] W. Riedel, K. Thoma, S. Hiermaier et al., "Penetration of reinforced concrete by BETA-B-500 numerical analysis using a new macroscopic concrete model for hydrocodes," in Proceedings of 9th International Symposium on Interaction of the Effect of Munitions with Structures, Berlin, Germany, May 1999.

[28] L. J. Malvar, J. E. Crawford, J. W. Wesevich, and D. Simons, "A plasticity concrete material model for DYNA3D," International Journal of Impact Engineering, vol. 19, no. 9-10, pp. 847-873, 1997.
[29] Y. S. Tai, T. L. Chu, H. T. Hu, and J. Y. Wu, "Dynamic response of a reinforced concrete slab subjected to air blast load," Theoretical and Applied Fracture Mechanics, vol. 56, no. 3, pp. 140-147, 2011.

[30] J. Dong, J. H. Zhao, D. F. Zhang, and Y. Li, "Research on dynamic response of concrete-filled steel tube columns confined with FRP under blast loading," Shock and Vibration, vol. 2019, Article ID 8692310, 18 pages, 2019.

[31] LS-DYNA, Keyword User's Manual, Version 971, Livermore Software Technology Corporation, Livermore, CA, USA, 2006.

[32] H. Kimura, M. Itabashi, and K. Kawata, "Mechanical characterization of unidirectional CFRP thin strip and CFRP cables under quasi-static and dynamic tension," Advanced Composite Materials, vol. 10, no. 2-3, pp. 177-187, 2012.

[33] A. A. Mutalib, M. H. Mussa, and H. Hao, "Effect of CFRP strengthening properties with anchoring systems on P-I diagrams of RC panels under blast loads," Construction and Building Materials, vol. 200, pp. 648-663, 2019.

[34] H. Draganić and D. Varevac, "Analysis of blast wave parameters depending on air mesh size," Shock and Vibration, vol. 2018, Article ID 3157457, 18 pages, 2018.

[35] F. Zhang, C. Wu, H. Wang, and Y. Zhou, "Numerical simulation of concrete filled steel tube columns against blast loads," Thin-Walled Structures, vol. 92, pp. 82-92, 2015.

[36] J. L. Pan, M. Luo, and J. J. Zhou, "Dynamic responses and failure mechanism of reinforced concrete cylindrical column wrapped with CFRP under blast loading," Journal of Tianjin University, vol. 43, pp. 755-761, 2010.

[37] UFC 3-340-02, Structures to Resist the Effects of Accidental Explosion, US Department of Defence (USDOD), Washington, DC, USA, 2008.

[38] M. Momeni, M. A. Hadianfard, C. Bedon, and A. Baghlani, "Numerical damage evaluation assessment of blast loaded steel columns with similar section properties," Structures, vol. 20, pp. 189-203, 2019. 